\title{
PHRÓNESIS EN FEDÓN Y PROTRÉPTICO
}

MARÍA GABRIELA CASNATI ${ }^{1}$

RESUMEN: Más allá de la discusión abierta acerca de si existe en Aristóteles un período platónico o académico e, incluso, si el Protréptico puede ser incluido dentro de él, en el presente trabajo nos proponemos resaltar el aspecto interesante -aunque poco trabajado- de la estrecha relación entre el tratamiento de la phrónesis en el Fedón y en el Protréptico. Para ello partiremos del análisis del concepto de phrónesis en el Fedón, donde encontramos una doble aproximación al término que representa tanto el fin más deseable a alcanzar como así también aquella sabiduría práctica que nos permite evaluar adecuadamente ciertas situaciones de la vida. A continuación, retomaremos esta doble vertiente platónica de la phrónesis como medio y como fin de la vida buena en algunos fragmentos seleccionados del Protréptico para mostrar cómo Aristóteles adhiere a la concepción antropológica platónica en función de un alma rectora que somete al cuerpo y cuya función más excelente debe ser el centro o télos de la vida humana. Encontramos que la phrónesis, además de permitir al hombre filosofar y alcanzar la contemplación y el conocimiento, exhibe también una dimensión práctica en tanto fundamento del buen uso del cuerpo para vivir del mejor modo posible.

Palabras clave: Fedón - Protréptico - Phrónessis - Filosofía.

ABSTRACT: Beyond the open discussion about whether there is a Platonic or Academic period in Aristotle and, even, whether the Protrepticus can be included within it, in this paper we intend to highlight the interesting point although not so often examined- of the narrow relationship between the treatment of phrónesis in the Phaedo and in the Protrepticus. In order to do so, we will start from the analysis of the concept of phrónesis in the Phaedo, where we find a double approach to the term that represents both the most

\footnotetext{
${ }^{1}$ UBA. E-mail: mariagcasnati@gmail.com.

Fecha de recepción: 18/10/2021; fecha de aceptación: 9/12/2021

DOI: https://doi.org/10.46553/sty.30.30.2021.p81-100
}

Stylos. 2021; 30 (30); pp. 81-100; ISSN: 0327-8859; E-ISSN: 2683-7900 
desirable end to be achieved as well as that practical wisdom that allows us to adequately evaluate certain situations in life. Next, we will return to this double platonic aspect of phrónesis as a means and as an end of the good life in some selected fragments of the Protrepticus to show how Aristotle adheres to the Platonic anthropological conception in terms of a guiding soul that subdues the body and whose most excellent function must be the center or télos of human life. We find that phrónesis, in addition to allowing men to philosophize and achieve contemplation and knowledge, also exhibits a practical dimension as the foundation of the proper use of the body to live in the best possible way.

Keywords: Phaedo-Protreptic - Phrónesis - Philosophy.

\section{INTRODUCCIÓN}

Más allá de la discusión abierta acerca de si existe en Aristóteles un período platónico o académico e, incluso, si el Protréptico puede ser incluido dentro de él, en el presente trabajo nos proponemos resaltar el aspecto interesante -aunque poco trabajado- de la estrecha relación entre el tratamiento de la phrónesis en el Fedón y en el Protréptico. Para ello partiremos del análisis del concepto de phrónesis en el Fedón, atendiendo especialmente al pasaje 66c-69c, donde emerge una doble caracterización del término: por un lado (66c-67b), se dice que es la purificación del alma la que libera del influjo perturbador al cuerpo y que esa purificación es necesaria para alcanzar la phrónesis; $\mathrm{y}$, por otro (69b8-c3), la phrónesis es presentada como un medio necesario para obtener la purificación del alma. Dentro de esta sección, propondremos una lectura del texto que -en línea con la interpretación de C. J. Rowe- entiende que no hay contradicción entre ambas aproximaciones, ya que en el primer caso el término phrónesis designa un tipo de comprensión que resulta inaccesible al filósofo en vida, pero que en el contexto de la propia existencia el término tiene un alcance más limitado y designa simplemente la lúcida apreciación, realizada en la presente vida misma, de lo que 
es verdaderamente valioso por oposición a lo que es solo aparentemente valioso. A continuación, retomaremos esta doble vertiente platónica de la phrónesis como medio y como fin de la vida buena en algunos fragmentos seleccionados del Protréptico para mostrar cómo Aristóteles adhiere a la concepción antropológica platónica en función de un alma rectora que somete al cuerpo y cuya función más excelente debe ser el centro o télos de la vida humana. Encontramos que la phrónesis, además de permitir al hombre filosofar y alcanzar la contemplación y el conocimiento, exhibe también una dimensión práctica en tanto fundamento del buen uso del cuerpo para vivir del mejor modo posible. A partir del análisis de los fragmentos escogidos intentaremos mostrar cómo la reflexión aristotélica del Protréptico recupera la doble vertiente de la phrónessis en tanto designa la forma más elevada del saber, esto es, el saber verdadero y filosófico y, en ese sentido, es eminentemente teorética (contenido fundamental de la philosophía y sinónimo de la sophía), sin descuidar la importancia del cultivo de la phrónesis y su utilidad para la vida práctica.

Si nuestra interpretación es acertada, podremos concluir que Aristóteles acuerda con el planteo platónico del Fedón para quien alcanzar la phrónesis es importante como un instrumento en nuestra vida, sin que eso implique dejar de considerarla el fin último al que aspira el alma. El estagirita, por su parte, entiende que la phrónesis es necesaria en nuestra vida práctica aunque, al mismo tiempo, se vuelve indispensable para alcanzar el mejor modo de vida que no es otro que aquel que conoce teoréticamente la verdad y los principios primeros. Señalaremos, finalmente, que esta similitud se da justamente en dos obras que pueden encuadrarse dentro del mismo interés protréptico o exhortativo: por un lado, el ateniense se esfuerza por convencer a los seguidores de Sócrates de que su muerte es parte de una enseñanza que debe acercarlos a la vida filosófica; por otro, el estagirita insta a filosofar (seguramente a potenciales seguidores de escuelas rivales) para alcanzar el mejor modo de vida que él propone.

Stylos. 2021; 30 (30); pp. 81-100; ISSN: 0327-8859; E-ISSN: 2683-7900 


\section{PHRÓNESIS EN EL FEDÓN}

La exquisita pluma platónica presenta a un Sócrates que defiende su forma de vida y, específicamente en esta obra, su elección del modo de enfrentar una muerte que se aproxima inexorablemente. Resulta importante delimitar la figura del genuino filósofo, que será quien desprecia involucrarse con los placeres propios del cuerpo para volverse hacia su alma y alejarse, en la medida en que puede, de lo corpóreo. Se distancia de los "así llamados placeres" ( lo que "se dice" que es placentero y lo que él personalmente considera placentero. Aceptar la existencia de "otros" placeres, más ligados al alma que al cuerpo, permitiría pensar que para Sócrates el alma no sería solo un principio cognitivo, sino que también es capaz de experimentar placer en su actividad. En tal sentido, Sócrates se presenta esperanzado en su encuentro, tras la muerte, con dioses sabios y buenos (63b-c), no se irrita al abandonar a sus amigos ante la inminencia de que se encontrará con "buenos dueños y compañeros" (69e) e, incluso, confía en que si el alma parte en buenas condiciones hacia lo divino, inmortal y sabio, "una vez llegada allí, le corresponde ser feliz" (81a). Para explicar esta actitud de confianza se desarrolla la así llamada "apología de Sócrates" (63e-69e), que consiste en la defensa de la vida filosófica como preparación para la muerte, pero una "muerte que el filósofo experimenta aun viviendo". ${ }^{2}$ Es en este contexto que emerge una valoración negativa de lo corpóreo -que causa no solo distracciones y enfermedades, sino que es origen incluso de guerras, sublevaciones y contiendas-, y también se delinea la oposición entre lo mezclado y lo puro, el no tener tiempo libre ( $\dot{\alpha} \sigma \chi 0 \lambda i ́ \alpha, 66 \mathrm{~d} 2$ ) y la $\sigma \chi 0 \lambda \eta ́$ (ligando siempre el primer término al comercio con el cuerpo y el segundo a la filosofía).

Se afirma que el cuerpo resulta un impedimento si se lo toma como compañero en la investigación: el filósofo debe desligar el alma del cuerpo si quiere alcanzar la phrónesis. Es en esta línea (65a9) donde aparece por primera vez en el diálogo el término phrónesis, con el sentido de aquel fin que se quiere alcanzar. A continuación (66b1-67b6), en el marco del discurso que los "genuinos filósofos" se dicen unos a otros -que recordemos se pre-

${ }^{2}$ Cf. Casertano (2015: 66).

Stylos. 2021; 30 (30); pp. 81-100; ISSN: 0327-8859; E-ISSN: 2683-7900 


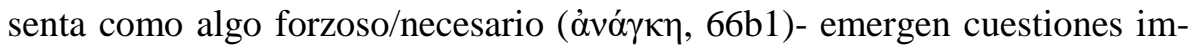
portantes. En primer lugar, encontramos dos sentidos de muerte que se superponen: uno real (según el cual la muerte es el alma que vive separada del cuerpo) y otro metafórico (donde estar muerto es el alma que, aun en vida del hombre, se distancia del cuerpo y de sus necesidades propias). De cualquier modo, ambos sentidos de muerte tienen el mismo fin: llegar a la verdad ( $\dot{\alpha} \lambda \eta \theta \dot{\eta} \varsigma, 66 \mathrm{~b} 7,66 \mathrm{~d} 7,67 \mathrm{~b} 1)$ y a la inteligencia/sabiduría ( $\varphi \rho \circ \eta \dot{\sigma} \sigma \varepsilon \omega \varsigma, 66 \mathrm{e} 3$;

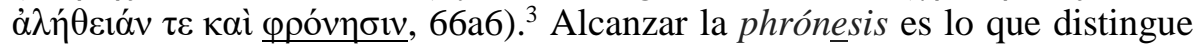
al verdadero filósofo, algo que es retomado en $79 \mathrm{~d}$ al afirmar que cuando el

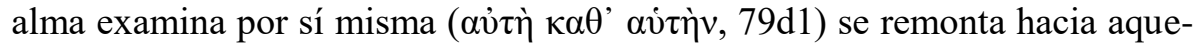
llo que es puro, siempre existente e inmortal, y en virtud de que es congénere

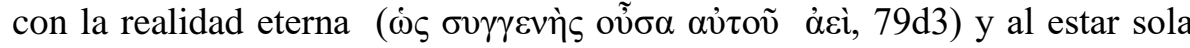
por sí misma, cesa en el extravío y permanece siempre en el mismo estado, y

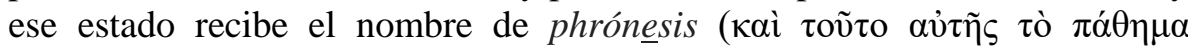

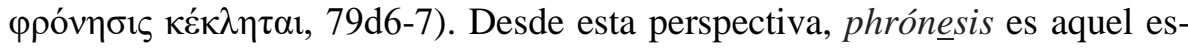
tado o condición o afección o disposición $(\pi \alpha ́ \theta \eta \mu \alpha, 79 \mathrm{~d} 7)$ del alma que, separada de las demandas del cuerpo en su condición encarnada, permanece siempre igual y en compañía de lo inmortal. Incluso, tal como Sócrates le explica a Simias en el desarrollo del argumento de la reminiscencia, "nuestras almas existían ya entonces, antes de venir a la figura humana, separadas del cuerpo y poseían phrónesis"4 (76c12), donde es significativo que el único atributo que se predica explícitamente del alma separada del cuerpo en todo el Fedón es justamente la posesión de phrónesis de esta línea. De allí que en estos pasajes pueda traducirse el término como "sabiduría" (Vigo,

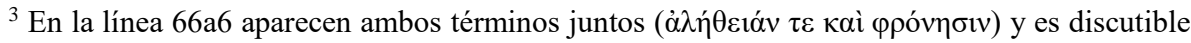
si deben ser considerados como sinónimos o no. WILLIAMSON (1904: 127) sostiene que aquí Platón distingue intencionalmente ambos términos: mientras $\dot{\alpha} \lambda \eta \dot{\eta} \theta \varepsilon \alpha^{\prime} v$ debe ser entendida co-

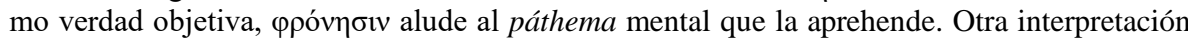
(con la que concordamos) y en línea con el sentido de la argumentación de estas líneas, consiste en reconocer que el conocimiento verdadero solo será posible una vez que el alma esté en sí y por sí misma; y que aquí, mientras el cuerpo sea un elemento disruptivo en su asociación con el alma, esta se encuentra alejada de la verdad y el conocimiento/sabiduría (entendidos como sinónimos) debido a las demandas del cuerpo. En este último sentido, cf. WhiTE (1989: 48).

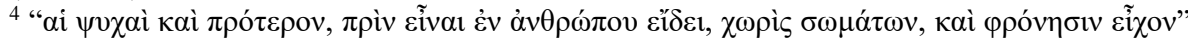
(76c11-12).
}

Stylos. 2021; 30 (30); pp. 81-100; ISSN: 0327-8859; E-ISSN: 2683-7900 
Eggers Lan) o "inteligencia" (Casertano), para acentuar el aspecto teorético del saber propio del ser inmutable. Se trata de un puro saber contemplativo que conforma el ideal a alcanzar para acceder a la verdad. Es el pensamiento en su forma más alta, es inteligir aquello que es inteligible.

Sócrates deberá esforzarse por convencer a sus interlocutores de que los que cultivan rectamente la filosofía se ejercitan en el morir y que en ningún otro lado se encontrará la phrónesis de modo más puro que en el Hades (nueva aparición del término en 68b4, con el mismo sentido). Una gran dificultad radica en que la mayoría de los hombres cree que, para quien no encuentra agradable aquellos placeres ligados con el cuidado del cuerpo ni toman parte de ellos -y acá asoma en el texto un nuevo sentido de muerte ${ }^{5}$ "no vale la pena estar vivo, sino que quien no se preocupa para nada de los placeres que se obtienen a través del cuerpo anda bastante cerca de estar muerto" (65a6-7). En contraste -sostiene Sócrates- el filósofo se halla ya muerto en vida a todas estas cosas y se dedica principalmente a su alma. Dada la definición de muerte como "el abandono del cuerpo por parte del alma" (64c4-5), ${ }^{6}$ Sócrates afirma que alcanzar ese estado constituye el objetivo de quien filosofa rectamente. Quien así haya actuado no temerá, pues, la llegada de la muerte en tanto dedicó sus esfuerzos a separarse de las demandas corpóreas en el mayor grado posible, no permitiendo que el alma se distraiga y sea engañada en la búsqueda de la verdad. Una vez en ese estado, "hay esperanza de que alcancen aquello que amaron a lo largo de su vida, y lo que amaban es la phrónesis" (68a1-2): nueva aparición del término como aquella meta a alcanzar por el alma una vez separada definitivamente del cuerpo.

\footnotetext{
${ }^{5}$ A los dos sentidos de muerte mencionados antes, se puede agregar el que aparece aquí: la muerte considerada como algo negativo que implica no procurarse los placeres corpóreos, únicos bienes por los que vale la pena vivir. Se retoma en $68 \mathrm{~d}$ : "todos los demás juzgan que la muerte se cuenta entre los males mayores".

${ }^{6}$ Unas líneas después, en 67d4-5, se reformula la definición de muerte en términos de "libera-

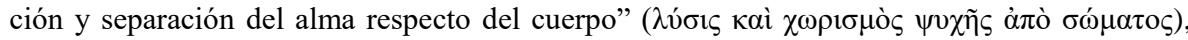
mientras que en $64 \mathrm{c}$ la muerte es definida como separación del cuerpo por parte del alma en términos evaluativamente neutros. Es posible que, tras haber enfatizado que el cuerpo y lo corpóreo son fuente de perturbación e impedimento para la actividad del alma, se reformule la caracterización anterior y se presente a la muerte como algo deseable para el filósofo y, en ese sentido, la separación es a la vez liberación para el alma. Cf. Rowe (1993: ad loc).
}

Stylos. 2021; 30 (30); pp. 81-100; ISSN: 0327-8859; E-ISSN: 2683-7900 
Podemos preguntarnos en qué consistirá esta acción del alma que en vida se concentra sobre sí misma, desligada todo lo posible de los sentidos. Es muy interesante en este punto el cambio de perspectiva en el análisis platónico: se pasa de lo que el filósofo puede esperar cuando su alma esté separada del cuerpo, a cómo el filósofo debe actuar, durante su vida, para alcanzar dicho momento en un estado adecuado. ${ }^{7}$ En ese sentido, phrónesis no aludirá a un pensamiento abstracto que se desentiende del mundo sensible, sino que consistirá más bien en un modo de vida dedicado a la filosofía ( $\dot{\varepsilon} v$

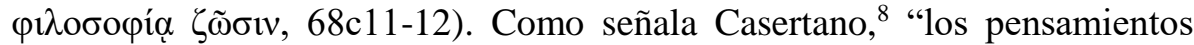
del filósofo siempre conciernen a este mundo, porque busca su significado, precisamente: la verdad". Sócrates afirma que el alma razona del mejor modo cuando está librada a sí misma, sin ser perturbada por los sentidos y que es en el razonamiento cuando se le hace manifiesto algo de lo que es ( $\tau$ oṽ

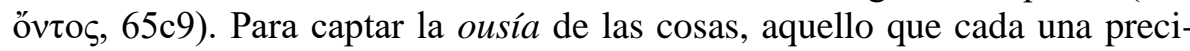
samente es, el alma debe concentrarse en sí misma y alejarse del cuerpo. Y si bien nadie se negaría a aceptar que existe algo justo en sí mismo, y algo bello y algo bueno, solo el alma -alejada de los sentidos- podrá considerarlo de modo preciso y aproximarse a su conocimiento.

Ahora bien, apelar a lo inteligible para explicar el mundo que nos rodea desde una perspectiva filosófica, tiene consecuencias metafísicas y epistemológicas (Fedón 78d-79a) pero también, y fundamentalmente en este contexto, consecuencias prácticas. Todo el discurso protréptico que Sócrates despliega en el Fedón puede entenderse como el intento de mostrar y explicar su actitud frente a la vida y a la muerte para exhortar a sus seguidores y movilizarlos respecto de su propia praxis y de su propia consideración de qué sea la existencia humana. Es mostrarles que para el filósofo alcanzar la muerte, y específicamente estar muerto, constituye el mejor y más noble modo de vida. ¿Cómo dirige, pues, su vida el filósofo para alcanzar tal fin? La condición del éxito es tener un pensamiento sin mezcla con lo sensible, esto es, purificado de las turbaciones del cuerpo. En tal sentido debe entenderse la insistencia en la purificación: un modo de vida puro será aquel que el filósofo experimenta "en vida" cuando "está muerto" a las pasiones y de-

${ }^{7}$ Cf. White (1989: 52).

${ }^{8}$ Cf. CASERTANo (2015: 67).

Stylos. 2021; 30 (30); pp. 81-100; ISSN: 0327-8859; E-ISSN: 2683-7900 
seos que lo esclavizan. Esta purificación permitirá conocer las Formas y también reconocer a los particulares sensibles en su relación con ellas.

En este contexto se resignifica el concepto de phrónesis. La metáfora monetaria de la virtud, ${ }^{9}$ anclada en el plano de la acción humana, muestra que sin la phrónesis, nuestras acciones consideradas valientes y moderadas no son más que simples remedos ${ }^{10}$ de virtud que no poseen nada sano ni ver-

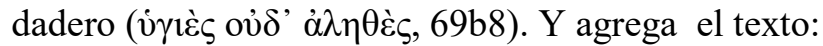

"Pero, en verdad, puede que la moderación, la justicia y la valentía no sean realmente sino una especie de purificación (kátharsís) de todas esas cosas, y que la propia sabiduría (phrónesis) sea una especie de medio de purificación (katharmós)" (69b8-c3).

Según nuestra interpretación, este pasaje continúa la distinción anterior entre el verdadero filósofo y el amante del cuerpo. Este último solo busca acrecentar el placer y disminuir el dolor con su modo de actuar; mientras que el verdadero filósofo, en sus acciones y experiencias cotidianas, considera, en cambio, el placer, el dolor, el miedo y demás pero en relación con la

\footnotetext{
${ }^{9}$ Escapa a los límites de este trabajo analizar el pasaje 68d2-69e4, donde se señala que la valentía (andréia) y la moderación (sophrosýne) solo pertenecen a quien realmente es filósofo. Frente a ello, el común de la gente utiliza los términos en el sentido corriente (o, como dirá después, la moderación en su modalidad ingenua) y considera temperantes a los que son temperantes por intemperancia, en tanto dominan algunos placeres (esto es, tiene la capacidad de mantener una disposición tranquila de austeridad y mesura respecto de los deseos apetitivos) solo en vista de otros placeres. Mientras que el verdadero moderado o temperante, modera los placeres en vista de la phrónesis. Como señala VIGO (2009: ad loc) "lo que quiere significar Sócrates al describir la forma corriente de la moderación como el resultado de un cierto tipo de desenfreno, se comprende mejor cuando se atiende al plano estrictamente motivacional: quienes se abstienen de determinados placeres, por temor a quedar privados de otros, solo exteriormente parecen comportarse del modo en que lo reclama la virtud de la moderación, ya que, desde el punto de vista de la motivación interna de sus acciones, sigue siendo el placer el que provee la pauta última para la orientación de su comportamiento". En este marco, la metáfora monetaria del intercambio de virtudes (Fedón 69a6-c3) concluye que la posesión de la sabiduría es lo que distingue entre un modo ingenuo o corriente y el modo verdadero de entender la virtud. Cf. White (1989: 54-57), GoOCH (1974), LuCE (1944).

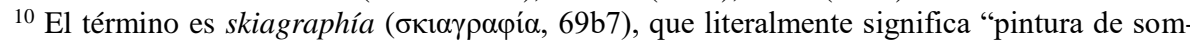
bras". Cf. la aclaración de CASERTANO (2015: ad loc), que cita otros usos platónicos del término para caracterizar a aquellas pinturas (por ejemplo, las de escenarios teatrales) que producen efectos de perspectiva mediante el uso de sombras, esto es, de claroscuros, y que alteraban las proporciones reales para dar una "ilusión" de realidad a los espectadores.
}

Stylos. 2021; 30 (30); pp. 81-100; ISSN: 0327-8859; E-ISSN: 2683-7900 
phrónesis. En este sentido, la phrónesis se constituye como un medio ${ }^{11}$ ineludible para alcanzar la virtud verdadera. Lo que se quiere señalar es que el verdadero filósofo no solo se purifica para llegar a alcanzar la phrónesis en su estado desencarnado, sino también en su praxis cotidiana es verdaderamente virtuoso en tanto "intercambia" placeres y dolores con la guía de la phrónesis que, desde esta perspectiva, constituye un medio para producir la virtud verdadera. Solo la presencia de la phrónesis hace que las virtudes sean verdaderas y sanas (a diferencia de lo que sucede con la visión popular y mercantilista de la virtud), en tanto en este nivel de análisis phrónesis indica la sabiduría que se manifiesta a través de una actitud o comportamiento prudente y reflexivo, que aporta el genuino fundamento racional que garantiza la convergencia adecuada entre sensaciones y pensamiento.

No deja de llamar la atención que mientras en 66c-67b, como vimos, se consideraba que era la purificación del alma la que la liberaba del influjo perturbador del cuerpo y que esa purificación era necesaria para que finalmente el alma desencarnada pudiera alcanzar la phrónesis, pocas páginas

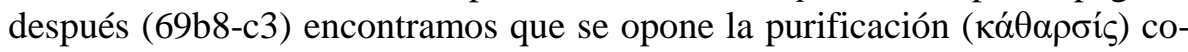
mo un determinado estado y se considera a la phrónesis como el medio por

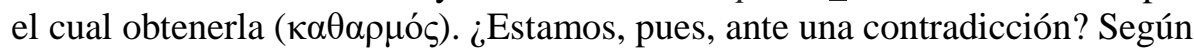
nuestro análisis no se trata de una contradicción, sino más bien de dos perspectivas diferentes de análisis de la phrónesis. En palabras de Rowe, ${ }^{12}$ no hay contradicción entre ambos pasajes, ya que en el primer caso el término phrónesis designaba un tipo de comprensión que resulta inaccesible al filósofo en vida, pero en el contexto actual de nuestra existencia el término tiene un alcance más limitado y designa simplemente la lúcida apreciación, reali-

\footnotetext{
${ }^{11}$ Si bien el análisis de esta diferencia excede los límites del presente escrito, hay que señalar que el pasaje dice que la moderación, la justicia y la valentía son una especie de kátharsis, mientras que la phrónesis es una clase de katharmós. Es discutible si el uso de dos términos análogos pero distintos intenta trazar alguna diferenciación. Rowe (1996: ad loc) encuentra evidente el contraste: kátharsis es el estado de purificación (si es que las virtudes son estados), y se opone a katharmós en tanto lo que produce ese estado. Consideramos que esta decisión es posterior a la consideración de la posible subordinación de la virtud verdadera a la phrónesis.

${ }^{12}$ Rowe (1996: ad 69c1); interpretación retomada por VIGO (2009: ad loc.).
}

Stylos. 2021; 30 (30); pp. 81-100; ISSN: 0327-8859; E-ISSN: 2683-7900 
zada en la presente vida misma, de lo que es verdaderamente valioso por oposición a lo que es sólo aparentemente valioso.

Lo dicho hasta aquí puede resumirse en el siguiente deseo socrático:

"Hay grandes esperanzas, amigo, para quien llega donde yo voy, de obtener allí en medida suficiente aquello que fue objeto de ocupación principal en nuestra vida pasada" (Fedón, 67b7-10).

Frente al inminente desenlace, Sócrates confía en que su alma irá al Hades donde entrará en contacto con la phrónessis, verdadera sabiduría inmutable y eterna. Pero ese encuentro solo será posible en tanto en vida fue un genuino filósofo, cuya praxis se orientó por la virtud verdadera fundada en la phrónessis que, en tanto examen permanente del alma, constituye la purificación que beneficia la vida del filósofo.

\section{PHRÓNESIS EN EL PROTRÉPTICO}

Nos interesa en este punto marcar la continuidad de esta doble vertiente platónica de la phrónesis como medio y como fin de la vida buena en algunos fragmentos seleccionados del Protréptico, para mostrar cómo Aristóteles adhiere a la concepción antropológica de su maestro en cuanto a un alma rectora que somete al cuerpo y cuya función más excelente debe ser el centro o télos de la vida humana. Esto aparece con claridad en los fragmentos $61 \mathrm{y}$ $62^{13}$ del Protréptico ${ }^{14}$ :

(B61) “(...) lo que está por naturaleza más dotado para gobernar y mandar es lo mejor, como lo es el hombre en relación con los demás animales. Así pues, el alma es mejor que el cuerpo (al estar más dotada para gobernar) y en el alma es mejor lo que posee razón y entendimiento. Tal es,

\footnotetext{
13 También en B59: "Además, de las partes que nos constituyen, una es el alma y la otra, el cuerpo, aquella gobierna y este es gobernado, la primera utiliza y el segundo subyace <al alma> como instrumento. Por lo demás, el uso de lo que es gobernado y del instrumento se

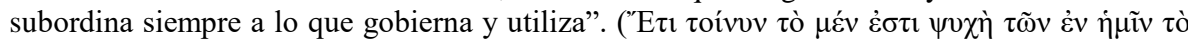

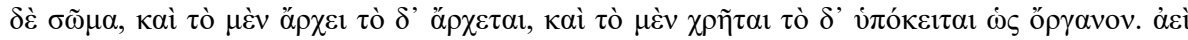

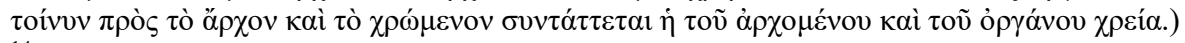

${ }^{14}$ Para todos los fragmentos se utilizará la traducción de VALLEJo CAMPOS (2005) que sigue la edición de Düring.
} 
efectivamente, lo que manda y prohíbe, y dice lo que debe y no debe hacerse". ${ }^{15}$

(B62) "Así pues, cualquiera que sea la virtud de esta parte, es necesario que sea la más deseable tanto, en general, para todos como para nosotros. Podría afirmarse, en efecto, según creo, que nosotros somos exclusiva o mayormente esta parte". ${ }^{16}$

Como vemos, también Aristóteles identifica lo más propio de la persona con su alma, donde el intelecto, en tanto lo más elevado y mejor, constituye el verdadero sí mismo, aquello que más genuinamente uno es (algo que aparece también en los fragmentos 17 y 23). Es importante notar que para Aristóteles el alma es superior porque posee autoridad, es dominante y rectora, y por tanto puede ordenar y prohibir qué debe hacerse y qué no. De modo que cuando la mejor parte del hombre, esto es, la parte racional de su alma, ${ }^{17}$ alcanza su excelencia, entonces su poseedor está bien dispuesto o está bien gobernado. Como señala Seggiaro, ${ }^{18}$ si el hombre no dispusiese de esta capacidad de poder determinar qué necesita y qué lo perjudica, es decir, si no dispusiese del pleno ejercicio de sus competencias deliberativas y no estuviese gobernado por ellas, su vida estaría dominada por sus impulsos instintivos.

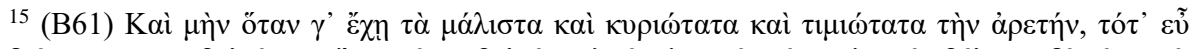

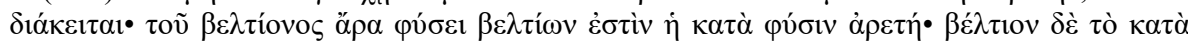

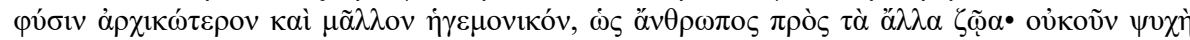

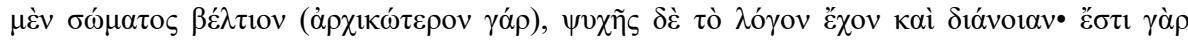

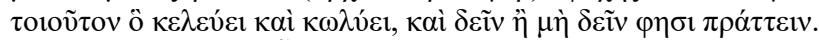

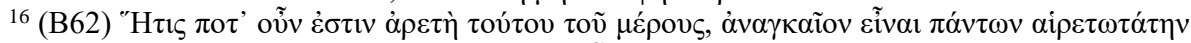

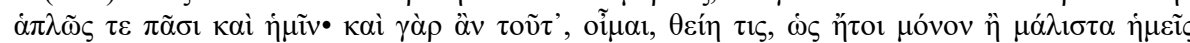

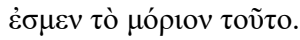

${ }^{17}$ Por supuesto, en el Fedón no se distinguen partes del alma (algo que sí encontramos, por ejemplo, en República y Fedro), sino que la oposición se da entre el cuerpo y el alma. Sin embargo, es claro que las apetencias del cuerpo perturban al alma, que puede verse contaminada por los males del cuerpo (66b) y por tanto hay que purificarla. Es notable que Sócrates afirme que el viaje al Hades se presenta con buenos auspicios para el hombre "que juzgue ha-

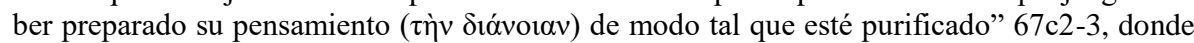
diánoia aparece como sinónimo de psykhé.

${ }^{18}$ Cf. SegGiaro (2019: 122).

Stylos. 2021; 30 (30); pp. 81-100; ISSN: 0327-8859; E-ISSN: 2683-7900 
En el Fedón, ambas cuestiones se afirman explícitamente. Por un lado, al responder a la objeción de Simias del alma-armonía, Sócrates afirma el carácter directriz del alma en tanto que de todas las cosas que hay en un hombre no hay otra que "gobierne ("丷 $\rho \chi \varepsilon ı v)$ que no sea el alma, especialmente si es sensata ( $\left.\varphi \rho v_{v} 1 \mu \mathrm{ov}\right)$ " (94b4-5); de aceptar que es como una armonía, entonces dirigiría "todas aquellas cosas de las que se dice que ella misma se compondría", cuando más bien "se $<\mathrm{les}>$ opone poco menos que en todo durante toda la vida, $\mathrm{y}<\mathrm{las}>$ domina en todas las formas <posibles $>$ " $(94 \mathrm{c} 10$ d2). Por otro lado, se opera una asimilación del alma con el intelecto o la razón o la facultad de razonar o, si se quiere, con el principio cognitivo con el cual se busca la phrónessis. Leemos que el alma "entra en contacto con la verdad" cuando intenta examinar algo sin la interferencia del cuerpo (65b9),

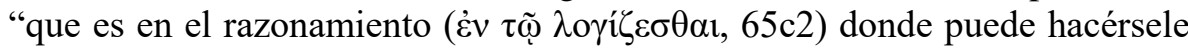
manifiesto algo de lo que es, y que sin duda el alma "razona del mejor mo-

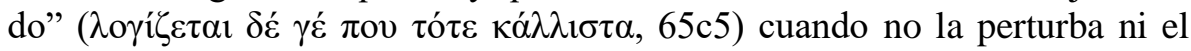
oído, ni la vista, ni ninguna otra sensación. ${ }^{19}$ Por cierto, también en Platón el alma se identifica con el sí mismo, con el verdadero yo: cuando Critón amigo fiel de Sócrates, que se preocupa por los aspectos "prácticos" pero no llega a entender el significado profundo de las palabras escuchadas ${ }^{20}$ le pre-

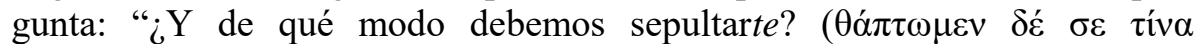

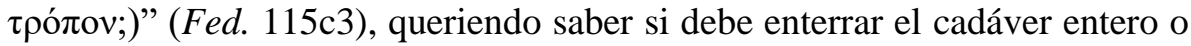
solo las cenizas en una urna tras su incineración (alternativa que aparece en $115 \mathrm{e}$ ), Sócrates retoma la pregunta y la reinterpreta en su sentido más pro-

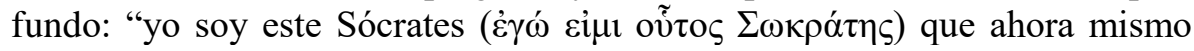
está dialogando" mientras que Critón "cree, más bien, que yo soy ese cadá-

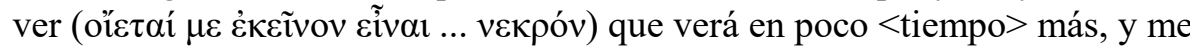
pregunta cómo debe sepultarme ( $\pi \tilde{\omega} \varsigma \mu \varepsilon \theta \dot{\alpha} \pi \tau \eta) "$. Esto es, Sócrates retoma el pronombre personal contenido en la pregunta (sepultarte) y amonesta cariño-

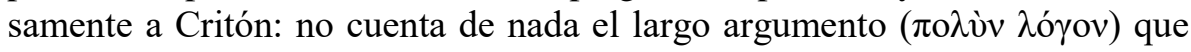

\footnotetext{
${ }^{19}$ La cuestión del cuerpo como un obstáculo peligroso para la vida buena y la filosofía como una actividad que promueve el buen uso del cuerpo para vivir lo mejor posible también aparece en el fragmento B8. Cf. Megino (2006: 139).

20 Cfr. CASERTANo (215: 17-18), quien enumera todas las apariciones de Critón en los distintos diálogos y sus intervenciones en el Fedón.
} 
ha desarrollado para mostrar que, una vez que beba el veneno, él ya no permanecerá entre ellos sino que se irá con los bienaventurados. El maestro se desilusiona en tanto los argumentos y el mito ofrecidos ${ }^{21}$ parecen haber sido en vano. De otro modo, todos sabrían que Sócrates, su persona, quien él es, no se identifica con el cadáver que quedará tras su ejecución y que será enterrado, sino que más bien él es su alma que partirá a otro sitio (Fed. 115c6e8).

Ahora bien, antes de concentrarnos específicamente en la continuidad del concepto de phrónesis en ambas obras, no podemos dejar de señalar cierto desacuerdo entre los especialistas. Mientras W. Jaeger afirma que el Protréptico fue escrito para exaltar el ideal educativo de la Academia, que se funda en el concepto de phrónesis como pura contemplación y equivalente del conocimiento filosófico, y que ese es el sentido que retoma Aristóteles en dicha obra, ${ }^{22}$ para I. Düring el Protréptico es una obra madura que, si bien tiene un origen platónico, expresa una filosofía propia y original. ${ }^{23}$ Sin pretender zanjar esta discusión, nuestro objetivo es relevar fragmentos aristotélicos para mostrar la continuidad en la recepción del concepto de phrónesis que ya analizamos en el Fedón.

Comenzaremos con los fragmentos 67 y 68, donde se pone de manifiesto el carácter teorético de la phrónesis:

(B 67) Así pues, al comparar un modo de ser con otro, nada hay más digno de ser elegido que la sabiduría ( $\varphi \rho \circ v \eta ́ \sigma \varepsilon \omega \varsigma)$, de la cual decimos que es facultad de lo más elevado que hay en nosotros. Efectivamente, la parte cog-

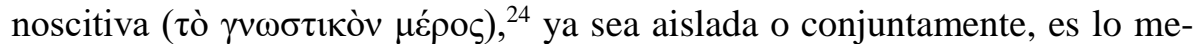
jor de toda el alma y su virtud es la ciencia. ${ }^{25}$

\footnotetext{
${ }^{21}$ Creemos que los argumentos y el mito final constituyen diferentes tipos narrativos que sustentan, ambos, la escena final de la obra.

22 JAEGER (1992: 97-101).

${ }^{23}$ DÜRING (1955: 81-97).

${ }^{24}$ Esta "parte cognoscitiva" claramente es el voûৎ (DüRING, 1961: 239).

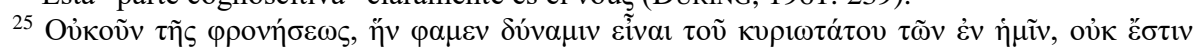

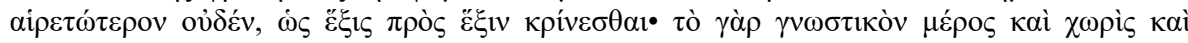

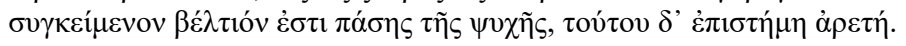

Stylos. 2021; 30 (30); pp. 81-100; ISSN: 0327-8859; E-ISSN: 2683-7900 
(B 68) En consecuencia, ninguna de las llamadas virtudes particulares es función de la sabiduría, pues esta es mejor que todas y, por otro lado, el fin producido es siempre superior a la ciencia que lo produce. Ciertamente, toda virtud del alma, de esta forma, ni es función suya, ni es la felicidad. Efectivamente, si <este saber> fuera de carácter productivo, sus productos serán diferentes de sí mismo, como lo es la casa respecto a la construcción, que no es parte de la casa, mientras que la sabiduría es parte de la virtud y de la felicidad. Pues nosotros decimos que la felicidad deriva de ella o es ella misma. $^{26}$

Tal como señala Megino ${ }^{27}$ aquí phrónesis es entendida como la ciencia de lo máximamente cognoscible, de los primeros principios y causas; por tanto, las virtudes morales (como la prudencia, la justicia o la valentía), que no pertenecen a la parte cognoscitiva del alma, están subordinadas a ella. En este sentido, podemos afirmar con Vallejo Campos $^{28}$ que la phrónesis en el Protréptico es entendida como un saber teorético y una virtud intelectual, que involucra la mera razón ${ }^{29}$ (a diferencia de las virtudes particulares de carácter ético). En estos fragmentos Aristóteles afirma la superioridad de la phrónesis respecto de los saberes productivos: el fin de estos últimos es la cosa producida, que es distinta de los saberes mismos y superior a estos en tanto que constituye su razón de ser. La sabiduría, por el contrario, consiste en una facultad cuyo ejercicio es un fin en sí mismo, dado que en el pensar y en la contemplación propios del conocimiento filosófico, que son obra suya, se cumple la excelencia o virtud que corresponde al hombre por naturaleza. En estas líneas, pues, Aristóteles defiende la superioridad de la vida teorética

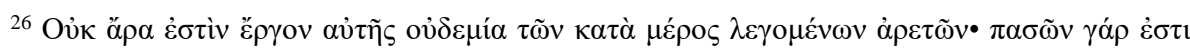

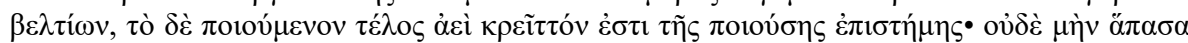

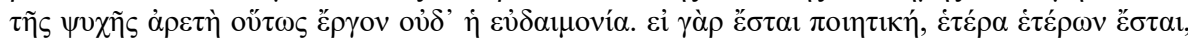

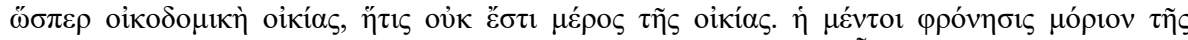

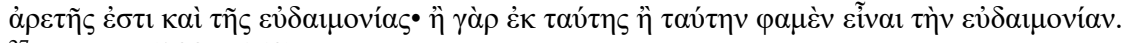

${ }^{29}$ DüRING (1961: 240) señala que, a pesar de la profundización que opera Aristóteles en su obra sobre el tratamiento de muchos temas y la consecuente terminología nueva que introduce, siempre conserva la misma fe en la razón y en la vida según el noûs del Protréptico en su Ética Nicomaquea (cf. B 78 y Ética Nicomaquea 1178 a 5-8).
}

Stylos. 2021; 30 (30); pp. 81-100; ISSN: 0327-8859; E-ISSN: 2683-7900 
(theoretikós bíos) y de la phrónesis, cuyo valor está por encima del ámbito político y del productivo.

Y en el fragmento 70 se concluye sobre el carácter puramente teorético de la phrónesis:

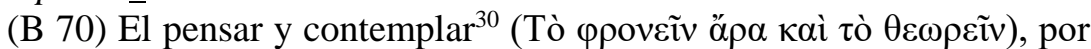
tanto, son función de la virtud ${ }^{31}$ y esto es para los hombres, de todas las cosas, lo más digno de ser elegido, como lo es también, en mi opinión, el ver para los ojos, lo cual es algo que uno desearía poseer, aunque por causa de ello no resultara nada aparte de la visión misma. ${ }^{32}$

En tanto el phroneîn, el contemplar, es función de la phrónesis, se ajusta perfectamente la comparación entre el phroneîn y el ver, dado el carácter teórico y desinteresado que distingue a la vista. Esto se repite en B72, ${ }^{33}$ donde se defiende la superioridad del conocimiento puro y se caracteriza (algo recurrente en Aristóteles) al deseo de saber como una tendencia que está fundamentada en la propia naturaleza humana. ${ }^{34}$

Ahora bien, junto con esta trascendencia teorética de la phrónesis que conlleva la vida contemplativa, encontramos también en el Protréptico una aproximación ligada a su carácter práctico. Comencemos con el fragmento B4:

(B4) Y esto es así en verdad. Pues, como dice el proverbio, el hartazgo engendra soberbia y la falta de cultura unida al poder trae como consecuencia la insensatez. Efectivamente, para los que tienen una mala condición en

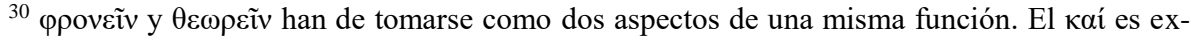
plicativo. MEGINO (2006:154).

${ }^{31}$ Acordamos con Berti quien señala que la areté que se menciona en esta línea es la phrónesis, de la cual el phroneîn y el theoreîn son su función.

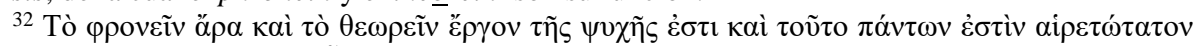

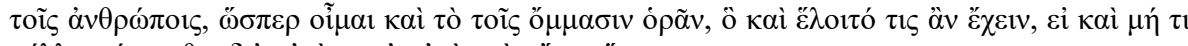

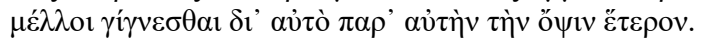

${ }^{33}$ (B72) "Por lo demás, si amamos el ver por sí mismo, esto prueba suficientemente que todos

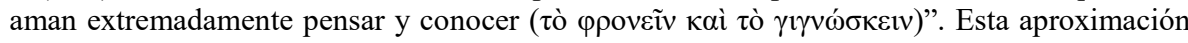
de carácter teorético a la phrónesis como contemplación la encontramos también en B94, B95, donde phrónesis es prácticamente sinónimo de sophía (cf. MEGINO, 2006: 159-160).

${ }^{34}$ Cf. VAllejo CAMPos (2005: 159-160). Para un detalle del argumento según el cual el amor a la vista demuestra que todo el mundo ama phroneîn en los fragmentos B70-77, cf. BERTI (1997: 436-437).
}

Stylos. 2021; 30 (30); pp. 81-100; ISSN: 0327-8859; E-ISSN: 2683-7900 
lo relativo al alma, la riqueza, la fuerza y la belleza no constituyen un bien, sino que cuanto más alto grado alcancen estas disposiciones, tanto mayores y más abundantes serán los daños para el que las posea sin la sabiduría $\left(\varphi \rho v^{\prime} \sigma \varepsilon \omega \varsigma\right)$. Pues "no dar a un niño una espada" significa que no hay que poner el poder en manos de hombres malvados. ${ }^{35}$

En este fragmento, en que Aristóteles apela a la sabiduría popular de un proverbio en su cometido de mostrar la conveniencia de emprender estudios filosóficos, emerge el carácter práctico de la phrónessis: supuestos bienes como la riqueza, la fuerza y la belleza no constituyen realmente un bien para quien carece de phrónessis; más bien, se vuelven dañinos si no son guiados por una dirección prudente. ${ }^{36} \mathrm{El}$ sentido con el que aparece en estas líneas el término phrónessis se ajusta a la definición de Ética Nicomaquea 1141b8-15 donde se afirma que "La prudencia (phrónesis) se refiere a las cosas humanas y a lo que es objeto de deliberación. En efecto, decimos que la función del prudente (tô̂ phronímou) consiste, sobre todo, en deliberar rectamente, y nadie delibera sobre lo que no puede ser de otra manera ni sobre lo que no tiene fin, y esto es un bien práctico. El que delibera rectamente, hablando en sentido absoluto, es el que es capaz de poner la mira razonablemente en lo práctico y mejor para el hombre". ${ }^{37}$

Este sentido reaparece en B53:

(B 53) No hay, pues, que rehuir la filosofía, si la filosofía es en verdad, según creemos, la adquisición y el uso del saber, y el saber ( бoфía) está entre los bienes más grandes. No debemos navegar hasta las columnas de Hércules por afán de lucro y arrostrar muchos peligros y, en cambio, por la sabiduría ( $\varphi \rho o ́ v \eta \sigma ı v)$, no esforzamos nada y andar escatimando. Ciertamente, es propio de esclavo afanarse por vivir, pero no por vivir bien, y seguir

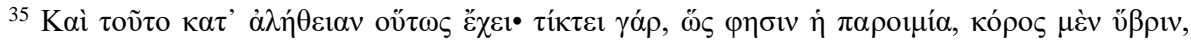

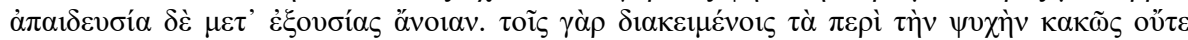

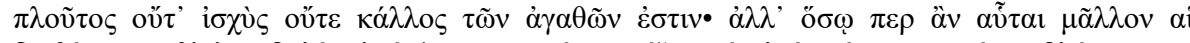

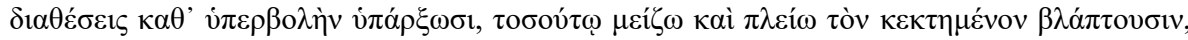

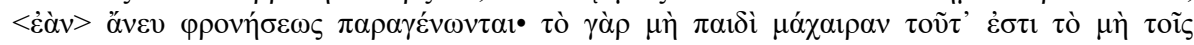

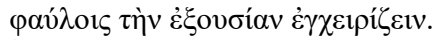

${ }^{36}$ Es evidente la similitud entre estas líneas citadas y el modelo de discurso expuesto por Platón en Eutidemo 280d-282d.

${ }^{37}$ Se utiliza la traducción de PALLí Bonet (1993).
}

Stylos. 2021; 30 (30); pp. 81-100; ISSN: 0327-8859; E-ISSN: 2683-7900 
las opiniones de la mayoría en lugar de considerar que sea la mayoría la que siga las nuestras, y lo es también ir en busca de riquezas sin cuidarse lo más mínimo de cosas más elevadas. ${ }^{38}$

En este fragmento Aristóteles utiliza sophía y phrónesis como términos sinónimos para indicar la necesidad de este tipo de saber para la vida buena y haciendo alusión no sólo al carácter teorético sino también al valor práctico del término. Es interesante notar, siguiendo en este punto a Megino, ${ }^{39}$ la insistencia en el uso de ejemplos para defender la insuficiencia que implica la adquisición y posesión de sabiduría si ella no es acompañada de un uso práctico, es decir, por la realización de buenas acciones que conduzcan a la felicidad; esto es, no basta con conocer el bien sino que hay que actuar bien. Dentro de esta misma línea de análisis, en el fragmento $\mathrm{B} 103^{40} \mathrm{y}$ trazando una analogía con el caso de la riqueza, Aristóteles distingue entre dos modos de vivir: el simple vivir ( $\tau$ ò $\zeta \tilde{\eta} v$ ) y el vivir felizmente o de un

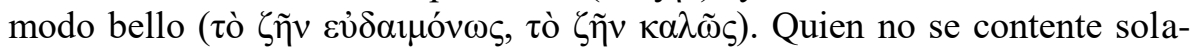
mente con vivir (como hace la mayor parte de los hombres) y quiera vivir felizmente, deberá empeñar el esfuerzo necesario para adquirir la phrónesis,

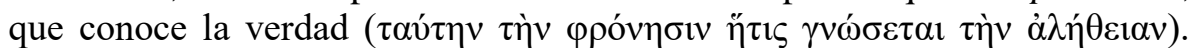
Por fin, la importancia de este sentido de la phrónesis también aparece en $\mathrm{B} 27,{ }^{41}$ donde se distingue un uso práctico de la razón que corresponde a la

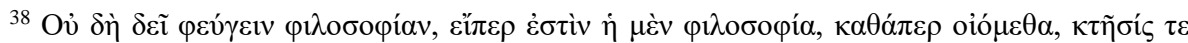

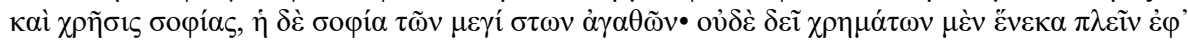

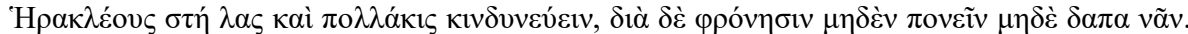

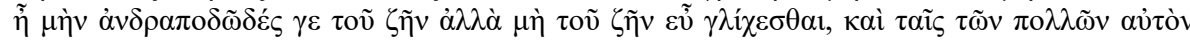

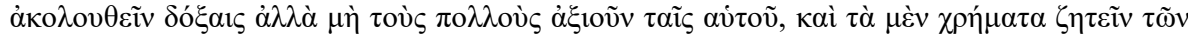

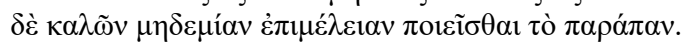

${ }^{39}$ Megino (2006: 152).

40 (B 103) Además de esto, igual que en el caso de la riqueza, no es la misma la propiedad que permite a los hombres vivir y aquella que les permite vivir felizmente, en relación con la sabiduría ( $\pi \varepsilon \rho \grave{~} \varphi \rho o v \eta ́ \sigma \varepsilon \omega \varsigma)$, tampoco es la misma, según creo, la que necesitamos para vivir meramente y para vivir bien. Con la mayoría hay que tener una gran indulgencia por su forma de proceder, pues hacen votos por ser felices, pero se contentan tan solo con poder vivir. No obstante, quien crea que no debemos sobrellevar la vida de cualquier modo, será ridículo si no soporta todo el esfuerzo necesario y no pone todo su empeño para llegar a poseer esta sabidu-

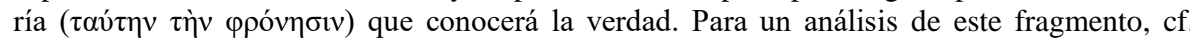
BERTI (1997: 438) y DÜRING (1961: 260-261).

${ }^{41}$ (B 27) De manera que aquellos pensamientos que son deseables por la mera contemplación

Stylos. 2021; 30 (30); pp. 81-100; ISSN: 0327-8859; E-ISSN: 2683-7900 
phrónessis y, por otro lado, una perspectiva teórica en la que se encuadra a la sophía: "Los pensamientos especulativos son valiosos en sí mismos y dentro de estos es preferible la sabiduría del intelecto ( que, tratándose de acciones, <son preferibles los pensamientos basados> en

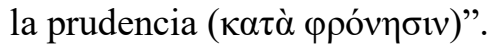

Habiendo trazado este recorrido y a modo de conclusión, interesa especialmente citar el fragmento 85 , donde encontramos un uso de phrónesis que conjuga su doble vertiente teorética y práctica:

(B 85) Ahora bien, la función del alma es sólo o mayormente pensar y razonar. Por tanto, es simple y fácil para cualquiera llegar a la conclusión de que vive más (propiamente) el que piensa rectamente y más (propiamente) que todos el que más alcanza la verdad, y que este es el que piensa y ejerce la actividad contemplativa en concordancia con la ciencia más rigurosa. Y la forma perfecta de vivir hay que atribuírsela también entonces a estos, es decir, a quienes ejercen la actividad de pensar y a los sabios. ${ }^{42}$

Encontramos aquí una importante conclusión en línea con una obra de corte exhortativo: quien con su alma piensa y ejerce la actividad contemplativa, que no es otra que la filosofía, alcanza su realización plena y actúa del mejor modo; en ese sentido, la filosofía coincide con la felicidad, que no es otra cosa que un modo de vida perfecto (fundado en el ejercicio del intelecto). ${ }^{43}$ Es por tanto sabiduría que contempla la verdad y también praxis filosó-

son más valiosos y superiores a los que son útiles para otra cosa. Los pensamientos especulativos son valiosos en sí mismos y dentro de estos es preferible la sabiduría del intelecto ( $\tau$ ov

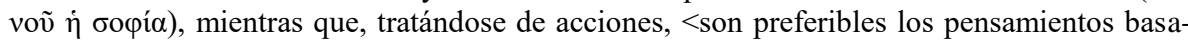

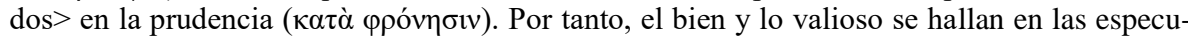

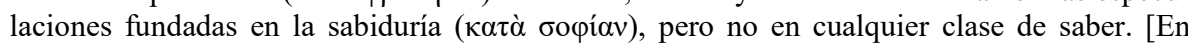
efecto, no toda comprensión es valiosa sin más, sino aquella que es propia del que ordena siendo sabio y del principio <que actúa> en el universo. Esta es inseparable de la sabiduría (бoфía $\alpha$ ) y podemos considerarla propiamente como tal.]

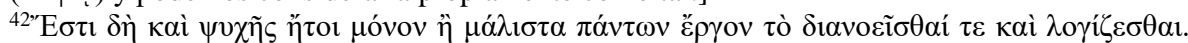

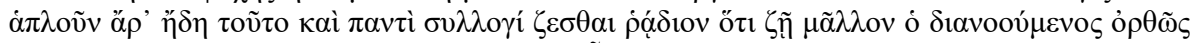

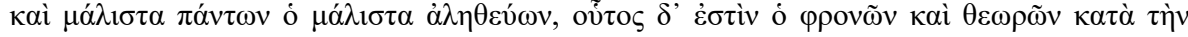

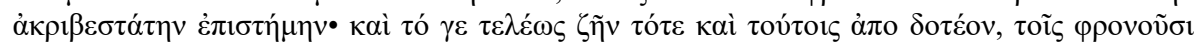

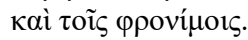

${ }^{43}$ BERTI (2014: 97). 
fica. Si nuestra interpretación de los pasajes es correcta, en ambos autores ${ }^{44}$ la phrónesis exhibe esta doble función: por un lado, es pensar recto y, en ese sentido, un fin en sí misma; por otro, es un saber que guía la acción humana. $\mathrm{Y}$ entre ambas aproximaciones no hay una separación tajante, en tanto la primera constituye el fundamento que lleva a la práctica la segunda. La phrónesis, que en estos fragmentos se identifica con la sophía, ${ }^{45}$ también desempeña una función práctica fundamental en tanto que aquello que elige el phrónimos en virtud de su actividad contemplativa es condición y guía de su acción. Lo que nos permitiría concluir que en los trabajos relevados ambos filósofos coincidirían en que el conocimiento más elevado es inescindible de la más genuina praxis filosófica.

\section{REFERENCIAS BIBLIOGRÁFICAS}

BERTI, E. La filosofia del "primo" Aristotele, Milano: Centro di Richerche di Metafisica dell' Università Cattolica del Sacro Cuore, 1997.

BERTI, E. Aristotele Protreptico: Esortazione alla filosofía, Turín: UTET, 2014.

Casertano, G. Fedone, o dell'anima. Drama etico in tre atti, trad., commento e noti di---, Napoli: Lofreddo, 2015.

DÜRING, I. "Aristotle in the Protrepticus", 81-98. En: L. de Raeymaeker and A. Mansion (eds), Autour d' Aristote, Louvain: Publ. Universitaires, 1955.

DÜRING, I. Aristotle's Protrepticus An Attempt at Reconstruction, Göteborg: Almqvist \& Wiksell, 1961.

Gooch, P. W. "The relation between wisdom and virtue in Phaedo 69a6c3", Journal of the History of Philosophy, 1974 12: 153-159.

\footnotetext{
${ }^{44}$ Limitamos nuestras afirmaciones al Fedón de Platón y al Protréptico de Aristóteles.

${ }^{45}$ En este discurso exhortativo respecto de la filosofía, Aristóteles utiliza el término бoøía prácticamente como sinónimo de $\varphi \rho o ́ v \eta \sigma r \varsigma$ (posiblemente, incluso, indique el aspecto teorético de la $\varphi \rho o ́ v \eta \sigma ı)$. Mientras que en el libro VI de la Ética a Nicómaco y en el marco del tra-

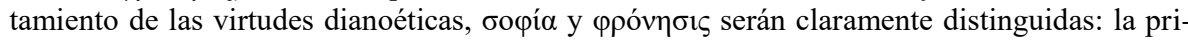
mera como conocimiento de lo necesario, la segunda como conocimiento de lo contingente.
}

Stylos. 2021; 30 (30); pp. 81-100; ISSN: 0327-8859; E-ISSN: 2683-7900 
JAEGER, W. Aristóteles, México: Fondo de Cultura Económica, 1992.

LuCE, J. V. "A discussion of Phaedo 69a6-c2", Classical Quarterly 1944 38: 60-64.

Megino RodríGuez, C. Protréptico, introducción, traducción y notas de---, Madrid: Abada, 2006.

PAllí Bonet, J., ARISTÓTEles, Ética Nicomáquea - Ética Eudemia, introd., trad. y notas de---, Madrid: Gredos, 1993.

Rowe, C. J., Plato, Phaedo, incl. bibliography and index, Cambridge: University Press, 1993.

SegGiaro, C. La concepción de filosofía en el Protréptico de Aristóteles. Su posible influencia platónica, Buenos Aires: TeseoPress, 2019.

VAllejo CAMPOS, A., ARISTÓTELES, Fragmentos, introd., trad. y notas, Madrid: Gredos, 2005.

Vigo, A., Platón, Fedón, trad., notas e introd. de---, Buenos Aires: Colihue, 2009.

White, D. Myth and Metaphysics in Plato's Phaedo, London and Toronto: Associated University Presses, 1989.

Williamson, H. The Phaedo of Plato, London: MacMillan, 1904.

Stylos. 2021; 30 (30); pp. 81-100; ISSN: 0327-8859; E-ISSN: 2683-7900 